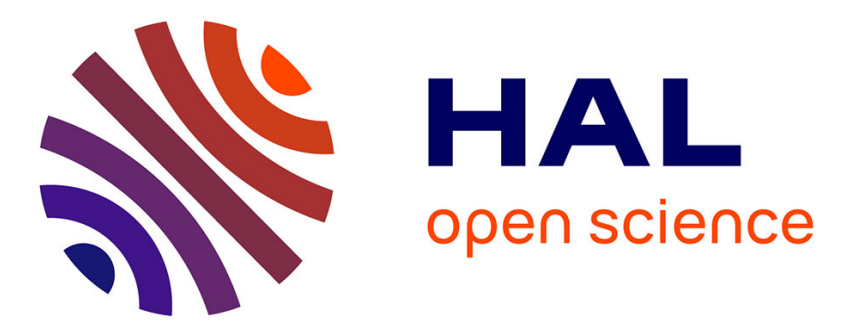

\title{
FeNi3 and Ni-based nanoparticles as electrocatalysts for magnetically-enhanced alkaline water electrolysis
}

Vivien Gatard, Raphaël Chattot, Vincent Martin, Jonathan Deseure, Marian

Chatenet, Déborah de Masi, Juan Manuel Asensio Revert, Pier-Francesco

Fazzini, Thierry Encinas, Stéphane Faure, et al.

\section{To cite this version:}

Vivien Gatard, Raphaël Chattot, Vincent Martin, Jonathan Deseure, Marian Chatenet, et al.. FeNi3 and Ni-based nanoparticles as electrocatalysts for magnetically-enhanced alkaline water electrolysis. Electrocatalysis, 2021, 11 (5), pp.567-577. 10.1007/s12678-020-00616-9 . hal-02953342

HAL Id: hal-02953342

https://hal.univ-grenoble-alpes.fr/hal-02953342

Submitted on 30 Sep 2020

HAL is a multi-disciplinary open access archive for the deposit and dissemination of scientific research documents, whether they are published or not. The documents may come from teaching and research institutions in France or abroad, or from public or private research centers.
L'archive ouverte pluridisciplinaire HAL, est destinée au dépôt et à la diffusion de documents scientifiques de niveau recherche, publiés ou non, émanant des établissements d'enseignement et de recherche français ou étrangers, des laboratoires publics ou privés. 
FeNi3 and Ni-based nanoparticles as electrocatalysts for magnetically-enhanced alkaline water electrolysis

Vivien Gatard ${ }^{1-2 \dagger}$, Déborah De Masi ${ }^{2}$, Raphaël Chattot ${ }^{1}$, Juan Manuel Asensio Revert ${ }^{2}$, Pier-Francesco Fazzini ${ }^{2}$, Thierry Encinas ${ }^{3}$, Vincent Martin ${ }^{1}$, Jonathan Deseure ${ }^{1}$, Julian Carrey $^{2}$, Bruno Chaudret ${ }^{2}$, Marian Chatenet ${ }^{1+}$

${ }^{1}$ Univ. Grenoble Alpes, Univ. Savoie Mont Blanc, CNRS, Grenoble INP*, LEPMI, 38000 Grenoble, France

${ }^{2}$ Laboratoire de Physique et Chimie des Nano Objets, INSA, Université de Toulouse, 135, Avenue de Rangueil, F-31077 Toulouse, France.

${ }^{3}$ Consortium des Moyens Technologiques Communs, Grenoble INP, CMTC, 38000 Grenoble * Institute of Engineering Univ. Grenoble Alpes

†Corresponding authors:

Tel.: +334 768266 54; E-mail address: vivien.gatard@ grenoble-inp.fr Tel.: +33 4768265 88; E-mail address: marian.chatenet@ grenoble-inp.fr 


\begin{abstract}
Today, hydrogen mainly originates from fossil sources (gas, oil and coal). Room temperature water electrolysis is an interesting alternative for renewable electricity storage, even if it is well-known that high-temperature systems are more efficient. To address this issue, we studied different non-platinum group metals (non-PGM) catalysts for alkaline Oxygen Evolution Reaction (OER) and Hydrogen Evolution Reaction (HER) by recording cyclic voltamperograms with a rotating disk electrode set up. Physicochemical characterizations of Ni-based and $\mathrm{FeNi}_{3}$-based catalysts were performed using transmission electron microscopy, X-ray Diffraction (XRD) and inductively coupled plasma mass spectroscopy (ICP-MS). Ni synthesized by the hot injection method is a good catalyst for HER, yet still less active than $\mathrm{Pt} / \mathrm{C} . \mathrm{FeNi}_{3}$ with and without a $\mathrm{Ni}$ surface doping are very good OER catalysts, slightly better than commercial unsupported $\mathrm{IrO}_{2}$. Electrochemical tests under alternating magnetic field (AMF) using these nanoparticles are ongoing, as these materials are compatible with AMFactivation.
\end{abstract}

\title{
Keywords
}

Oxygen Evolution Reaction (OER), Hydrogen Evolution Reaction (HER), Alkaline water electrolysis; nickel, iron carbide; magnetic nanoparticles. 


\section{Introduction}

Decarbonization of our society is an emergency. The use of hydrogen $\left(\mathrm{H}_{2}\right)$ as an energy vector could limit our dependence to fossil fuels, enabling governments and populations to face global warming issues and scarcity of critical materials (e.g. of batteries). Being the most abundant element (by number of atoms) on Earth (mostly in the form of water), hydrogen could be used as large-scale (ideally renewable) energy storage [1], and converted into electricity thanks to fuel cells (or in combustion engines, even if this latter solution is not as green) [2]. At present, the main hurdle in this scenario is that $96 \%$ of the global hydrogen production originates from steam reforming of natural gas or coal, which generates 2.5 and 5 tons of $\mathrm{CO}_{2}$ per ton of hydrogen, respectively [3]. A better way to produce hydrogen is water electrolysis. In this framework, a cyclic economy where the spare electricity generated by renewable energies would serve to produce dihydrogen $\left(\mathrm{H}_{2}\right.$, hereafter simply denoted as hydrogen) would be ideal $[4,5]$. Two main methods exist to generate hydrogen from electricity at near-room temperature (a strategy which is compatible with the unavoidable intermittent operation associated with renewable electricity storage): proton exchange membrane (PEM) electrolyzers and alkaline water electrolyzers (AWE). The first one presents several advantages, among which a higher efficiency $(67-82 \%$ vs. $\sim 60 \%$ in industrial AWE [6], a higher power density (max. $4.4 \mathrm{~W} \mathrm{~cm}^{-2}$ vs. max. $1 \mathrm{~W} \mathrm{~cm}^{-2}$, in industrial AWE). Most importantly, the PEM technology is already compatible with fast startup/shutdown, hence with intermittent operation, an important prerequisite if storage of renewable electricity is targeted [4]. However, PEM electrolyzers suffer from the expensive noble materials (e.g. Pt and Ir-based catalysts) required to catalyze both the OER and the HER that occur at the two electrodes of a water electrolyzer, while still resisting a highly acidic media and presenting sufficient durability in operation [7]. As a matter of fact, the durability of these materials in operation is still not granted, and many groups try to understand the phenomena at stake and to propose more stable materials 
[8][9][10][11][12][13]. Conversely, non-platinum-group-metal (PGM) catalysts can be used in alkaline water electrolyzers, leading to cheaper systems and reduced pressures on the availability of their core materials. These clear advantages, that promoted their industrial deployment since more than 5 decades, are however counterbalanced by their poorer electrical performances and their inability to operate in intermittent operations. In brief, one would like to adopt both the electrical advantages of PEMWE and the material ones of AWE [14].

Niether et al. recently demonstrated that nanoparticles (NPs) which combine magnetic and catalytic properties can be on-demand magnetically-activated by the application of a highfrequency alternating magnetic field (AMF), and showed that this combination of advantages could be a reality for an AWE) [15]. This new technique of magnetically-enhanced water electrolysis enabled the significant reduction of the water electrolysis voltage by enhancing the kinetics of the HER and the OER thanks to a pronounced localized heating of the magnetic NPs under AMF $[15,16]$ and, as the local heating effect is nearly instantaneous while the overall cell remains at room temperature, intermittent operation of AWE should be reached. More specifically, Niether et al. used iron carbide (FeC) nanoparticles, covered by a Ni shell [17]. Under magnetic excitation, the magnetization of the NPs oscillates at high-frequency between two positions, leading to a release of heat in their environment [17]. In order to achieve water electrolysis under AMF, two flow-cells were designed on purpose (a three electrode cell and a two electrode cell). They needed to fulfill several (sometimes antagonistic) properties: (i) be compatible with an insertion in the coil generating the AMF, (ii) enable current collection and electrochemical measurements, (iii) be compatible with diphasic flow management and separation of the gases (for the two-electrode cell), owing to the intense bubbles generation in the alkaline solution. Of course, the use of the AMF triggered many problems, such as intense electrical noise (in the current collectors and the electrodes); besides, the current collector materials had to be chosen so as to minimize eddy currents, not to overheat (burn) under AMF 
excitation. In the end, the design of the two cells was adapted to the morphology of the coils, the bubble coverage issue, the choice of current collector and of the catalyst materials (which should be magnetic and catalytic). Although in Niether et al. study, the demonstration of AMFenhanced AWE was obvious, one must admit that neither the cell design nor the electrode materials were fully optimized. For example, their catalysts showed low HER performance and a poor durability. Therefore, there is still room for improvements.

This paper attempts to proceed further and address one of the issues listed above; it particularly focuses on the choice of the catalyst materials, to enhance their catalytic properties (for the OER and for the HER); the other issues raised (including the catalysts' heating properties) will be addressed in complementary studies that have been initiated by our team. Optimizing the catalyst can be made by adjusting both the magnetic core and catalytic shell. It was hoped to reach better activities and durability by changing the $\mathrm{FeC}$ core into $\mathrm{FeNi}_{3}$. Therefore, in the present contribution, the catalysts tested are nanoparticles of $\mathrm{FeNi}_{3}, \mathrm{FeNi}_{3} @ \mathrm{Ni}$ (further enriched with $\mathrm{Ni}$ ), and different $\mathrm{Ni}$ particles, supported or not. It is important to precise that $\mathrm{Fe}-\mathrm{Ni}$ alloys and Ni-based catalysts in general [18] have previously proven their good performance and stability for OER, especially for catalysts containing 10 to $50 \%$ of $\mathrm{Fe}$ [19][20][21]. The same properties have even been reached with stainless steel electrodes, upon proper electrochemical activation [22,23]. The choice of $\mathrm{FeNi}_{3}$ comes from its good heating properties and activity for the Sabatier reaction [24]. In this study, the electrochemical activity of the materials has been measured with a RDE. The physicochemical properties were assessed using XRD, TEM and elemental analyses, made by ICP-MS. 


\section{EXPERIMENTAL SECTION}

\subsection{Nanoparticles Syntheses}

\section{Synthesis of Ni Nanoparticles with the 'Hot Injection' Method (NiHI)}

Pure unsupported Ni NPs were prepared using a slightly modified version of a synthesis protocol for PtNi NPs, referred to as the "hot injection" method, previously reported in [25]. Briefly, $575 \mathrm{mg}$ of $\mathrm{Ni}(\mathrm{II})$ 2, 4-pentanedionate (95\%, Alfa Aesar) and $736 \mathrm{mg}$ of 1, 2tetradecanediol reducing agent $(90 \%$, Sigma-Aldrich) were dissolved in a mixture of $120 \mathrm{~mL}$ dibenzylether ( $\geq 98 \%$, Sigma-Aldrich), $1.2 \mathrm{~mL}$ oleylamine ( $\geq 98 \%$, Sigma-Aldrich) and $1.2 \mathrm{~mL}$ oleic acid (tech. 90\%, Sigma-Aldrich). The mixture was first heated at a temperature of $T=$ $80^{\circ} \mathrm{C}$ under Ar flow for $30 \mathrm{~min}$, then heated to $T=240^{\circ} \mathrm{C}$. As soon as the targeted temperature was reached, $12 \mathrm{~mL}$ of a 1, 2 dichlorobenzene (99\%, Alfa Aesar) solution containing $7 \mathrm{mg}$ of Pt(II) 2, 4-pentanedionate (48\%, Alfa Aesar) were quickly injected in the reactor. Since Ni alone is not reducing under this reacting conditions, a low Pt atomic fraction (0.8 at.\%) was maintained in order to initiate the nucleation and growth of the Ni NPs (consequently these Pt atoms are buried in the Ni NPs core). The solution was then heated at $T=270^{\circ} \mathrm{C}$, and maintained under continuous stirring for $1 \mathrm{~h}$. After cooling down, $120 \mathrm{~mL}$ of ethanol were added to the mixture, then the product was collected by centrifugation, washed one time with toluene (Roth, $\geq 99.8 \%$ ) and 3 times with ethanol, and then freeze-dried. These NPs are noted $\mathrm{Ni}_{\mathrm{HI}}$ hereafter.

\section{Synthesis of Ni Nanoparticles with the polyol method (Nipolyol)}

A much easier and scalable approach to produce Ni NPs is offered by the polyol method. Here, $410 \mathrm{mg}$ of Ni(II) chloride hexahydrate (Puratronic 99.995\%, Alfa Aesar) were dissolved in $200 \mathrm{~mL}$ ethylene glycol (Rotipuran ${ }^{\circledR} \geq 99.9 \%$, Roth). To induce the nucleation of Ni NPs, $2.5 \mathrm{~mL}$ of a $5.8 \mathrm{mM}$ aqueous solution of $\mathrm{Pt}(\mathrm{IV})$ dihydrogen hexachloroplatinate hexahydrate were also added (resulting in an overall 0.8 at.\% Pt content). The $\mathrm{pH}$ of the solution was set to 
10 by dropwise addition of an aqueous $0.5 \mathrm{M} \mathrm{NaOH}$ (Suprapur, Merck) solution. The solution was heated to $T=160^{\circ} \mathrm{C}$ under Ar flow for $1 \mathrm{~h}$. After cooling down, the product was collected by centrifugation, washed 3 times with ethanol and then freeze dried. It is noted $\mathrm{Ni}_{\text {polyol }}$ hereafter.

Deposition of Ni Nanoparticles on antimony-doped tin oxide (ATO) aerogel support (Ni/ATO)

$8 \mathrm{mg}$ of Ni NPs prepared with the polyol method and $32 \mathrm{mg}$ of $\mathrm{SnO}_{2}$ aerogel doped with $\mathrm{Sb}(10$ at.\%) [26]were mixed in $40 \mathrm{~mL}$ toluene (thus targeting a total Ni mass fraction of 20 wt.\% on ATO). The product (noted Ni/ATO hereafter) was first sonicated (Elma, S10, ultrasonic frequency: $34 \mathrm{kHz}$ ) for $20 \mathrm{~min}$ in an ice bath, collected by centrifugation, washed 3 times with ethanol and then freeze-dried.

\section{Synthesis of FeNi3 and FeNi3@ Ni catalysts}

These NPs will be fully described in a forthcoming article [24]. Shortly, unsupported $\mathrm{FeNi}_{3} \mathrm{NPs}$ were synthesized by the co-decomposition of two organometallic precursors: $\left.\mathrm{Fe}\left(\mathrm{N}\left(\mathrm{Si}\left(\mathrm{CH}_{3}\right)_{3}\right)_{2}\right)_{2}\right)(1$ equivalent $)$ and $\mathrm{Ni}(\mathrm{iPr}-\mathrm{Me}-\mathrm{AMD})_{2}(5 \mathrm{eq})$ under 3 bar of $\mathrm{H}_{2}$ at $T=150^{\circ} \mathrm{C}$ for $24 \mathrm{~h}$ in the presence of stabilizers, palmitic acid.

The surface of these particles can be enriched with $\mathrm{Ni}$ (noted hereafter FeNi ${ }_{3} @ \mathrm{Ni}$ ) through decomposition of 0.5 eq of $\mathrm{Ni}(\mathrm{AMD})_{2}$ under 3 bar of $\mathrm{H}_{2}$ at $50^{\circ} \mathrm{C}$ during $24 \mathrm{~h}$ in the presence of pre-formed $\mathrm{FeNi}_{3} \mathrm{NPs}$ in mesitylene.

\subsection{Physicochemical characterizations}

The catalyst materials were thoroughly characterized using complementary techniques, as detailed below. Their morphology was investigated using transmission electron microscopy 
(TEM). Bright-field images in high resolution were acquired with a Jeol TEM 2010 apparatus baring a LaB6 filament operating at $200 \mathrm{kV}$ (point-to-point resolution $=0.19 \AA$ A). X-Ray energy dispersive maps (X-EDS) and scanning TEM high angular annular dark field micrographs (STEM-HAADF) were in occasion monitored using a Jeol 2100F- $200 \mathrm{kV}$ microscope, equipped with a field-emission gun, which was operated at $200 \mathrm{kV}$ (point-to-point resolution = $0.23 \mathrm{~nm})$.

The crystalline phases in presence were analyzed using X-Ray Diffraction; the diffractometer was a X'Pert Pro MPD (PANalytical) baring a copper anode, and the $\mathrm{K} \alpha \mathrm{Cu}$ wavelength (1.5419 $\AA$ ) was chosen for the measurements. The reflection-acquisition mode was used in the Bragg Brentano geometry.

The metal content was determined by ICP-MS. The apparatus was a Perkin Elmer, model NexION 2000c. The measurements were made in the standard and the collision mode (Kinetic Energy Discrimination, KED). The calibration curve was drawn by using metal standard solutions ( $\mathrm{Sn}, \mathrm{Sb}, \mathrm{Ir}, \mathrm{Pt}, \mathrm{Fe}$ ) of 2, 5, 10, 20 and $50 \mathrm{ppb}$ with an intern standard (2 ppb of Rh), in nitric media $\left(2 \% \mathrm{HNO}_{3}\right)$. Analysed masses of the studied elements are calculated regarding the dilution and the calibration curve with a minimum $\mathrm{R}^{2}$ of 0.9999 and an overlapping percentage of the intern standard ranging from $98 \%$ to $102 \%$. The software used was Syngistix for ICPMS Software v2.3.

\subsection{Electrochemical Characterization}

The catalytic activity of the nanoparticles was measured using a classical three-electrode setup, where the counter electrode (CE) was a Pt-mesh, the reference electrode a hydrogen electrode (RHE - Gaskatel), and the working electrode (WE) a thin-film deposit of the desired electrocatalyst on a glassy carbon rotating disk electrode (RDE, $0.196 \mathrm{~cm}^{2}$ ) embedded in a KEL-F cylinder (polychlorotrifluoroethylene, PCTFE). Note that in the short-term experiments 
performed here, no consequent issue regarding contamination of the working electrode (WE) by potential dissolution of the Pt counter electrode (CE) shall be expected. Prior to use the glassy carbon substrate was polished using mechanical grinding disks of P600, P1200 and P2400, and then with 3 and $1 \mu \mathrm{m}$ diamond polishing paste (Presi Mecaprex). Cleaning was performed through sequential baths of acetone - deionized (DI) water $(18 \mathrm{M} \Omega . \mathrm{cm})+$ ethanol DI water in a sonication bath during $10 \mathrm{~min}$ each, prior to ink deposition. The inks were composed by a mixture of 30:12:1 DI water, 2-propanol and 5 wt.\% Nafion (Aldrich). After dispersion/mixing in ultrasonic bath (Elma, S10, ultrasonic frequency: $34 \mathrm{kHz}$ ) for 10 to 15 min, they were drop-casted and spin-coated onto the glassy-carbon electrode and dried with a hairdryer for $\sim 5 \mathrm{~min}$, according to the methodology developed by Garsany et al. [27][28][29]. In order to compare the results described here with the literature, one should pay attention to the sonication method and the dispersion time, as it notably induces changes in electrochemical surface area [30,31]. In this study, dispersion/mixing procedure does not involve catalyst modifications, because different loadings of active material, ranging from $100 \mu \mathrm{g} / \mathrm{cm}^{2}$ to 3000 $\mu \mathrm{g} / \mathrm{cm}^{2}$, were obtained without changing the ratio between the components.

All measurements were recorded with a potentiostat (Biologic VMP3 Multi Potentiostat). The Ohmic drop (iR-drop) was determined by electrochemical impedance spectroscopy (EIS) at $100 \mathrm{kHz}$ and compensated at $80 \%$ for all experiments. A typical value of the high-frequency resistance was $3 \Omega$ in $1 \mathrm{M} \mathrm{KOH}$. A rotation rate of $1500 \mathrm{rpm}$ was chosen so as to ensure efficient removal of the gas bubbles formed at the WE and avoid mass-transfer limitation; the electrolyte was dilute aqueous potassium hydroxide (1 $\mathrm{M} \mathrm{KOH}$, prepared from 99.98\% KOH pellet, Sigma); it was purged with Ar during 10 min prior each experiments and kept under an Ar blanket at any time. One should note that such an electrolyte might contains traces of metals, but contamination should not be an issue, as neither long-term operation nor durability assessment had been performed in the present study. 
The catalysts activities for OER was measured by monitoring cyclic linear sweep voltammetry (LSV) ranging from $1.2 \mathrm{~V} v s$. RHE to $1.8 \mathrm{~V} v s$. RHE; similar measurement from $-0.7 \mathrm{~V} v s$. RHE to $0.2 \mathrm{~V} v s$. RHE were made to quantify their activity for the HER; in any case, these measurements were performed at a scan rate of $5 \mathrm{mV} / \mathrm{s}$. According to El-sayed et al. a lower scan rate could lead to a non-negligible risk of poisoning by bubbles and the detachment of the active layer [32], while higher potential scan rates would obviously make it difficult to reach quasi-steady-state. The cyclic voltammetry $(\mathrm{CV})$ were repeated multiple times for a given electrode, and repeated at least three times for reproducibility assessment. A surface pretreatment of five cycles at $100 \mathrm{mV} / \mathrm{s}, 2$ cycles at $20 \mathrm{mV} / \mathrm{s}$ before and after the OER CV ranging from 0.05 to $1.2 \mathrm{~V} v s$. RHE were done on each working electrode.

\section{RESULTS AND DISCUSSION}

\subsection{Physicochemical characterizations of the pristine catalyst materials}

$\mathrm{Pt} / \mathrm{C}\left(10\right.$ wt.\%) and commercial unsupported $\mathrm{IrO}_{2}$ catalysts were used as benchmark catalysts to compare with $\mathrm{Ni}$ and $\mathrm{FeNi}_{3}$-based materials. Their properties have already been described in [12][33].

Figure 1, 2 and 3 show representatives TEM images of the $\mathrm{Ni}$ and the $\mathrm{FeNi}_{3}$-based catalysts, respectively. Figure 1 (a) corresponds to the $\mathrm{Ni}_{\mathrm{HI}}$ nanoparticles; they are wellcrystallized spherical-shaped individual particles of ca. $69 \mathrm{~nm}$ mean size, based on the measurement of ca. 30 isolated NPs, and they are organized in large agglomerated structures, which is somewhat classical for unsupported NPs. Most of the particles are polycrystalline contrast from the TEM and high-resolution TEM images of Figure 1 (a) and Figure 1 (b), with evidences of twins and internal grain boundaries. Although the diameter value is based on few measurements of NPs, the TEM pictures show at low magnification a similar NP size, for all type of Ni NPs. 
Figure $1 \mathrm{~b}$ ) shows representative micrographs of the Ni/ATO $20 \mathrm{wt} . \%$ material at similar magnification than for $\mathrm{Ni}_{\mathrm{HI}}$. It is obvious that the material morphology is very different, the $\mathrm{Ni}$ NPs being here much smaller (ca. $5 \mathrm{~nm}$ in average diameter, based on the measurement of ca. 50 distinguishable particles), which is of course associated to the presence of the ATO support. In addition, it is difficult to distinguish the Ni NPs from the ATO substrate, owing to the nearsimilar $\mathrm{Z}$ and crystalline contrasts of the two materials (the same had already been noted by Cognard et al., for Pt/ATO NPs [26]). Figure 1 (c) corresponds to unsupported Ni NPs synthetized with the polyol method. The size of the isolated $\mathrm{Ni}_{\text {polyol }}$ particles is in that case intermediate (ca. $12 \mathrm{~nm}$ in average diameter, based on the measurement of ca. 50 distinguishable particles) between the two previous samples. Obviously, these unsupported NPs are organized in very large 3-dimentional agglomerates. We were not able to reach high magnification for $\mathrm{Ni}_{\text {polyol }}$ because the oxidized particles were changing rapidly, reduced by the electron beam. Indeed, one can see a brighter disk around all the Ni NPs, which indicates their surface oxidation.

One common feature of these materials is the organization of the Ni NPs in agglomerated structures, even for the ATO-supported ones (Ni/ATO). This point is important for the targeted application as, it has been shown, in many case that agglomerates of NPs heat significantly more than isolated NPs under AMF, although this is not a general rule [15,34]. 


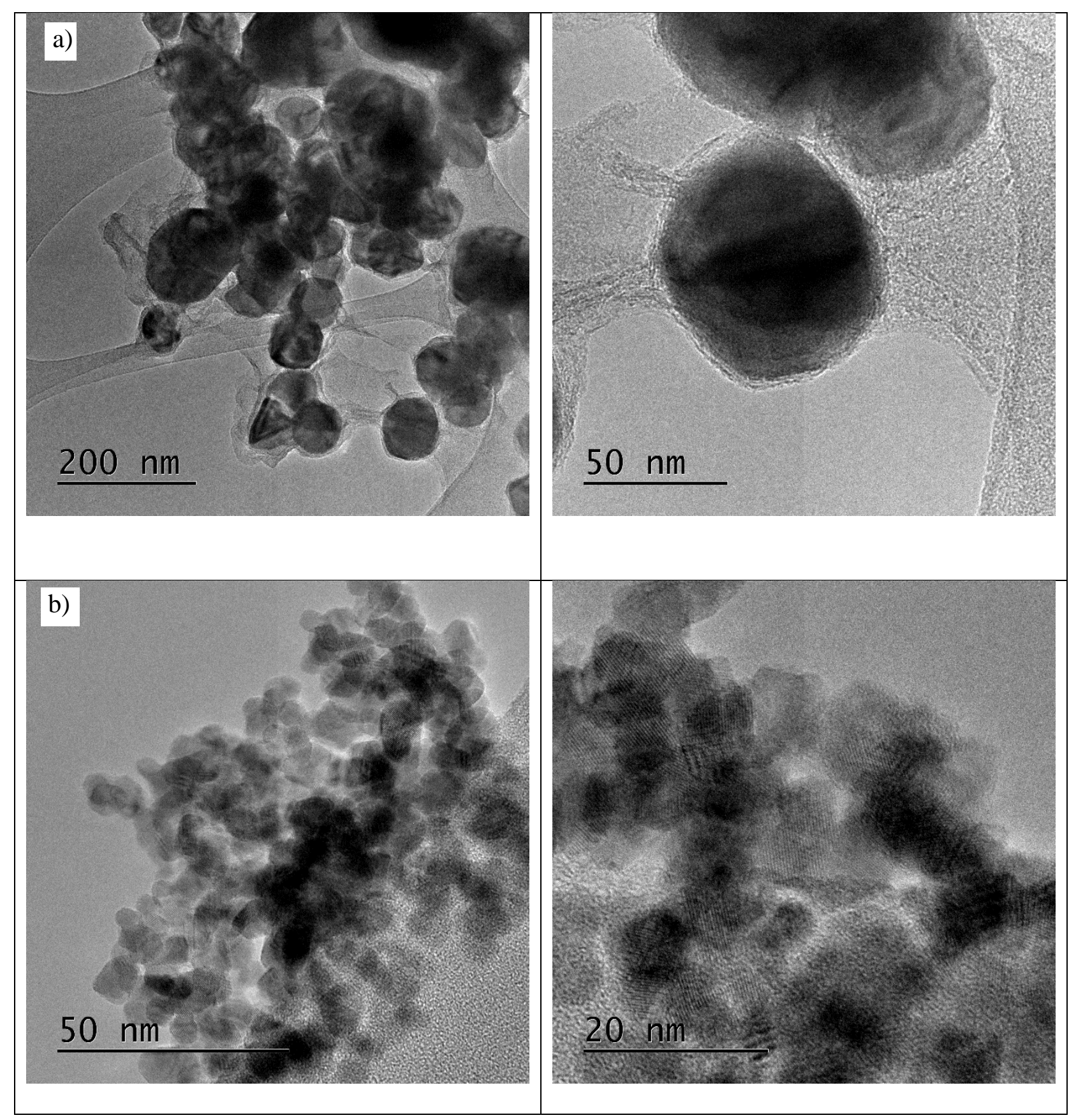




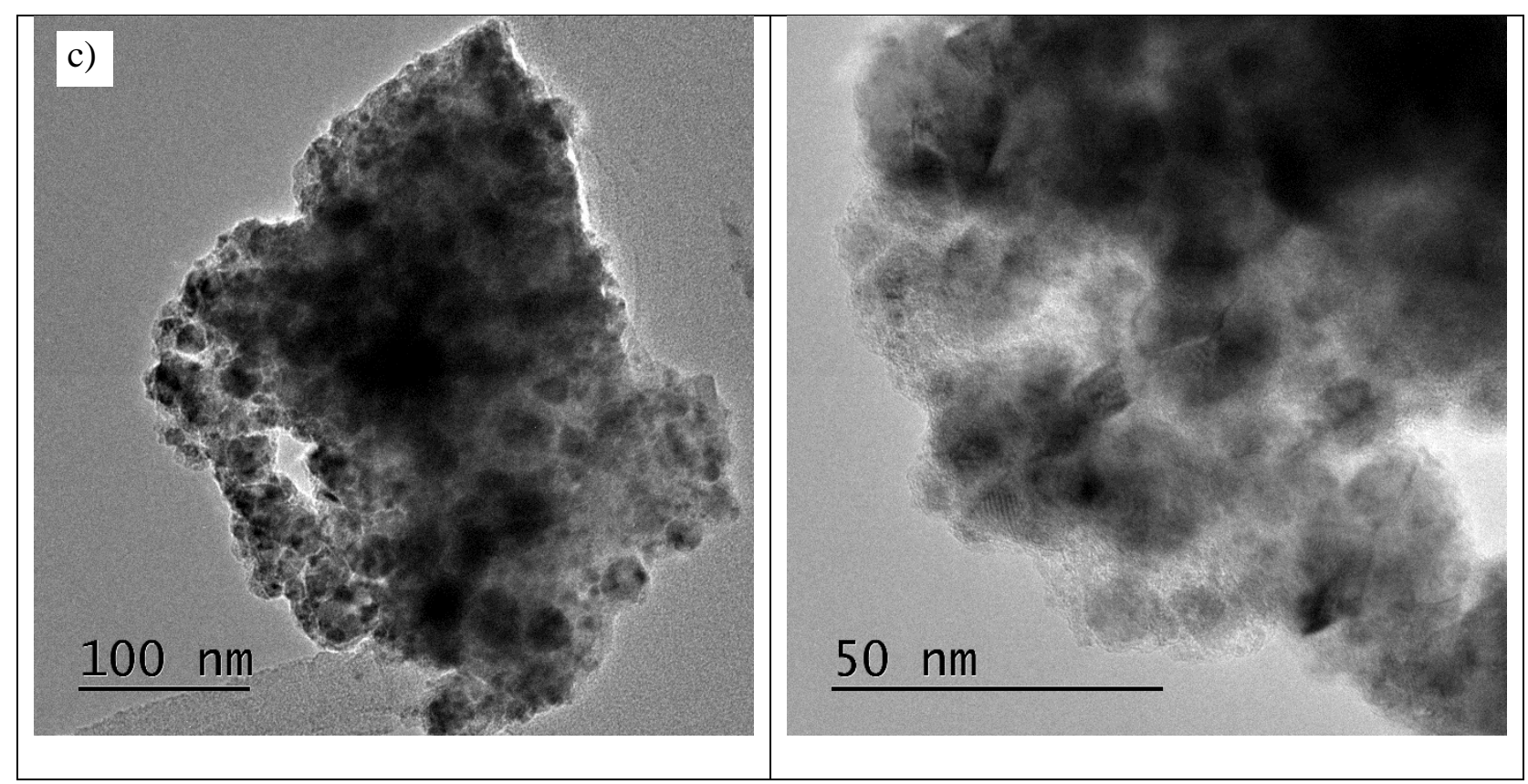

Figure 1: Representative TEM micrographs of the various unsupported $\mathrm{Ni}$ nanoparticles; (a) $\mathrm{Ni}{ }_{\mathrm{HI}}$, (b) $\mathrm{Ni} / \mathrm{ATO} 20$ wt.\% and (c) $\mathrm{Ni}_{\text {polyol. }}$.

Figure 2 shows representative micrographs of the unsupported $\mathrm{FeNi}_{3} \mathrm{NPs}$, and Figure 3 similar data for the unsupported $\mathrm{FeNi}_{3} @ \mathrm{Ni}$ NPs. The corresponding X-EDS elemental maps show that $\mathrm{Fe}$ and $\mathrm{Ni}$ are evenly-distributed in the $\mathrm{FeNi}_{3}$ core for the materials, while the STEM X-EDS indicate a Fe shell at the surface. FeNi3@Ni NPs have thus been synthesized to enrich the surface with $\mathrm{Ni}$, in order to have a better electrochemical activity. 

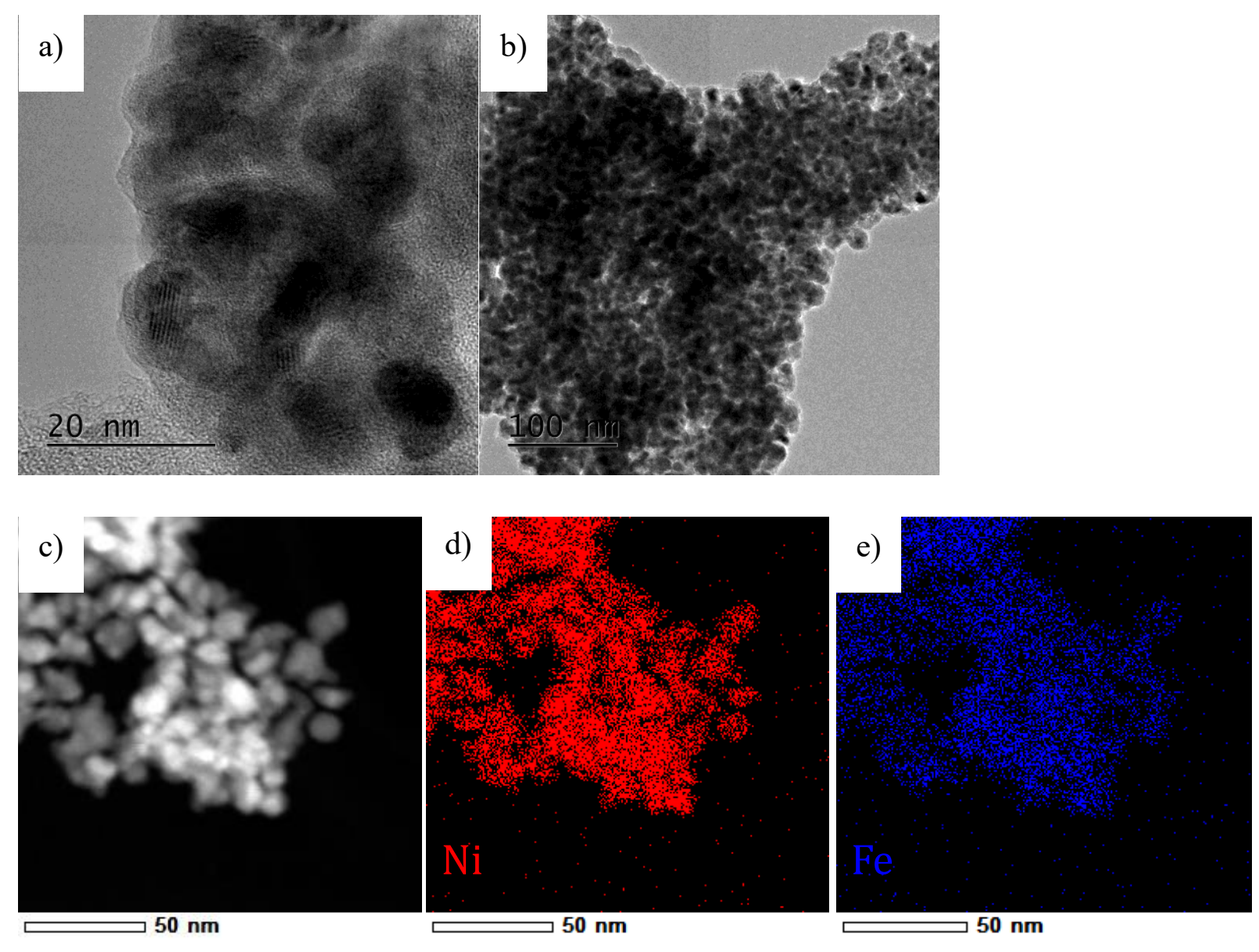

Figure 2: a) and b) TEM Images of the unsupported FeNi ${ }_{3}$ NPs. c) STEM-HAADF and X-EDS mapping of d) Fe et e) Ni.

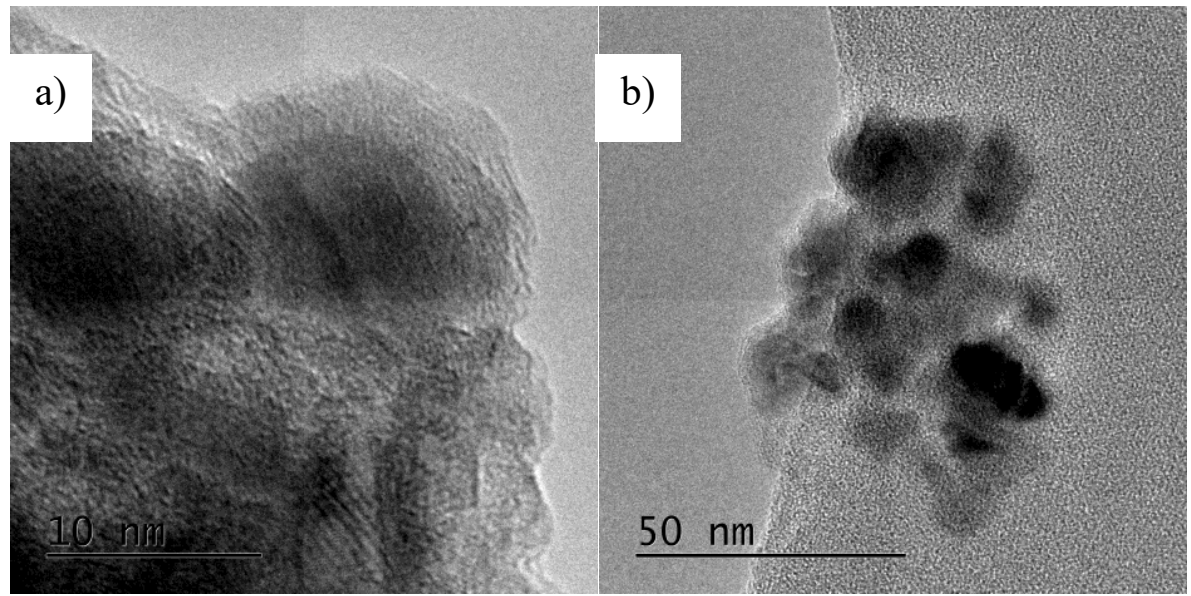



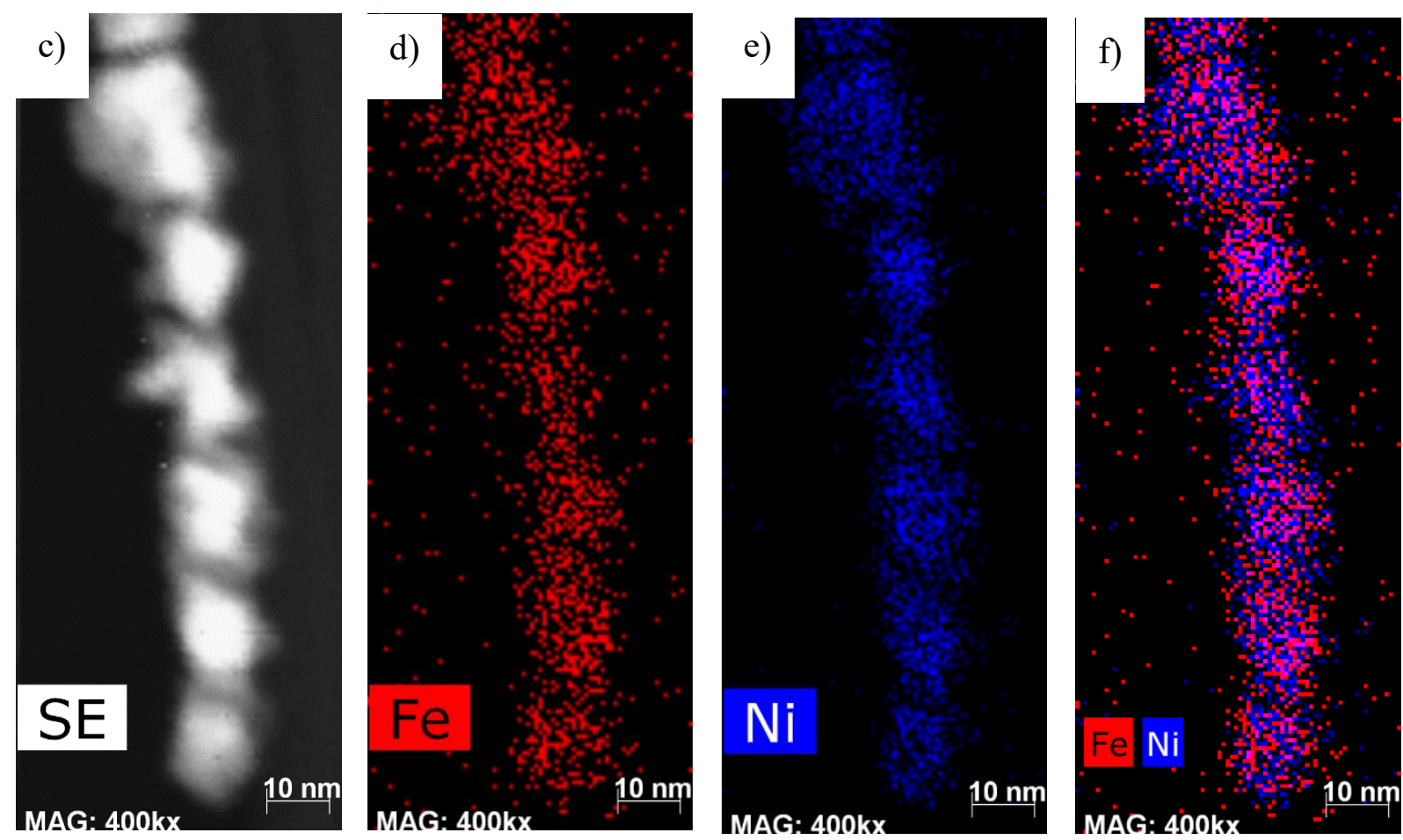

Figure 3a) and b) TEM image of FeNi3@Ni NPs and c) HAADF-STEM of FeNi3@Ni and X-EDS mapping of d) Fe et e) $\mathrm{Ni}$ and f) $\mathrm{Fe}$ and $\mathrm{Ni}$

In addition, the $\mathrm{FeNi}_{3}$ and $\mathrm{FeNi}_{3} @ \mathrm{Ni}$ display much smaller particle sizes than the pure unsupported $\mathrm{Ni}$ materials ( $\mathrm{Ni}_{\mathrm{HI}}$ and $\mathrm{Ni}_{\text {polyol }}$ ), the average particle diameter being ca. $17.3 \mathrm{~nm}$ and $18.6 \mathrm{~nm}$ for $\mathrm{FeNi}_{3}$ and $\mathrm{FeNi}_{3} @ \mathrm{Ni}$, respectively (values based on the measurement of ca. 200 isolated particles). However, the high-resolution TEM image of Figure 2(b) indicates that the crystallite size of the $\mathrm{FeNi}_{3}$ core might be even smaller, as individual crystallites and grain boundaries are obvious on this HRTEM micrograph.

The X-EDS analyses of the multi-metallic materials also revealed that the effective stoichiometry of the catalysts was close to the targeted ones for the Ni/ATO 20 wt.\%. Unsupported $\mathrm{FeNi}_{3}$ and $\mathrm{FeNi}_{3} @ \mathrm{Ni}$ SEM-XEDS analyses give $\mathrm{Fe}: 31 \%$, Ni: 69\% for $\mathrm{FeNi}_{3}$ and Fe: $22 \%, \mathrm{Ni}: 78 \%$ for $\mathrm{FeNi}_{3} @ \mathrm{Ni}$. 
The TEM analyses were complemented by powder XRD, both for the pure Ni materials (Figure 4) and for the iron-nickel based ones (Figure 5). In terms of crystalline phases, the Ni NPs synthesized by the hot injection method $\left(\mathrm{Ni}_{\mathrm{HI}}\right)$ are composed by a cubic and a hexagonal phase. Ni NPs synthesized with the polyol method $\left(\mathrm{Ni}_{\text {polyol }}\right)$ only display a cubic phase which is observed in the Ni/ATO too. ATO is composed by a $\mathrm{SnO}_{2}$ tetragonal phase. The broad diffusion peaks of the Ni/ATO suggest the presence of small or amorphous NPs in this sample, which agrees with the TEM pictures (this material was the one for which the Ni NPs are the smallest, and their contrast over the ATO support is poor).

The crystallite sizes have been derived from the area of the diffraction peaks using Scherrer's equation (more specifically, the values of the crystallites size have been obtained from the area and the half height of two well defined peaks - see Table 1).

The crystallite sizes for $\mathrm{Ni}_{\mathrm{HI}}$ are ca. $11.9 \pm 1.5 \mathrm{~nm}$ for the cubic phase and $12.9 \pm 2.9 \mathrm{~nm}$ for the hexagonal phase, much smaller than the apparent particle size for this material, which confirms the observations derived from the TEM analyses. Ni synthesized with polyol presents crystallites of $7.2 \pm 1.9 \mathrm{~nm}$ in its cubic phase (as unsupported Ni NPs, results obtained with the same peaks), while after being supported by ATO the crystallites grew up to $10.2 \pm 1.7 \mathrm{~nm}$; this size corresponds to the NP size derived from the TEM observation. The supported $\mathrm{Ni}_{\text {polyol }} \mathrm{NPs}$ are bigger because Ni NPs act as a reducing agent compared to the ATO so that the $\mathrm{Ni}_{\text {polyol }} \mathrm{NPs}$ get oxidized and grow in size. In any case, both NPs size values are within the error bars. Tetragonal $\mathrm{SnO}_{2}$ phase shows smaller crystallites of $4.8 \pm 0.3 \mathrm{~nm}$. Thus, the two Ni syntheses lead to similar cubic crystallites and only the Ni NPs synthesized by the hot injection method present a hexagonal Ni phase, at least in part. 


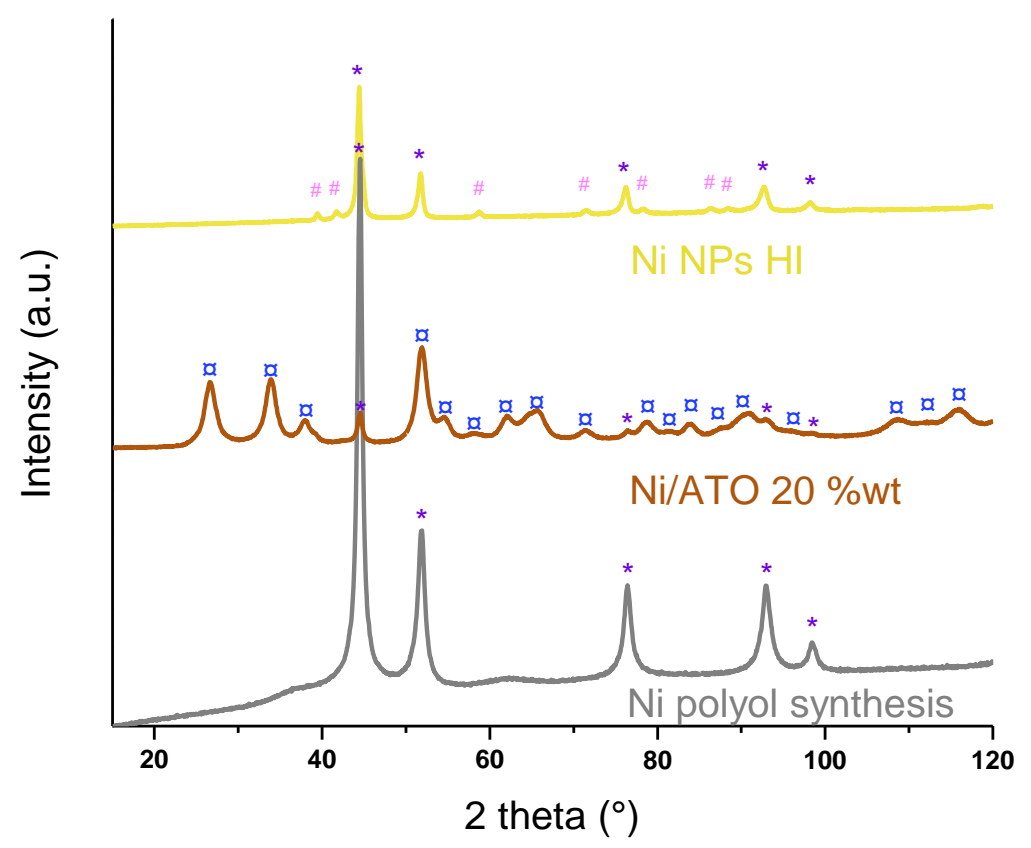

Figure 4 : X-ray diffractograms of (i) $\mathrm{Ni}_{\text {polyol }}$ synthesised by with polyol, (ii) $\mathrm{Ni}_{\mathrm{HI}} \mathrm{NPs}$ synthesised by the hot injection method, (iii) Ni/ATO $20 \mathrm{wt} . \%$. The star, the hash and the circles symbols correspond to cubic Ni (PDF card 00-004-0850), hexagonal Ni (PDF card 01089-7129), and tetragonal $\mathrm{SnO}_{2}$ (PDF card 04-003-0649), respectively.

The X-ray diffractograms of the $\mathrm{FeNi}_{3}$ nanoparticles, with and without $\mathrm{Ni}$ shell, are presented on Figure 5. In $\mathrm{FeNi}_{3}$, crystallites in the Ni cubic structure are observed, the sizes of which are ca. $4.6 \pm 0.3 \mathrm{~nm}$. The small broad peaks correspond to surface oxidation. The same observation is made for the $\mathrm{FeNi}_{3} @ \mathrm{Ni}$ material, the cubic Ni crystallites being of ca. $4.1 \pm 0.9$ nm. The background has, on purpose, not been removed. FeNi3 peaks are in fact very close to Ni peaks. A Mössbauer study was also undertaken to confirm the $\mathrm{FeNi}_{3}$ material, and will be further reported [24]. 


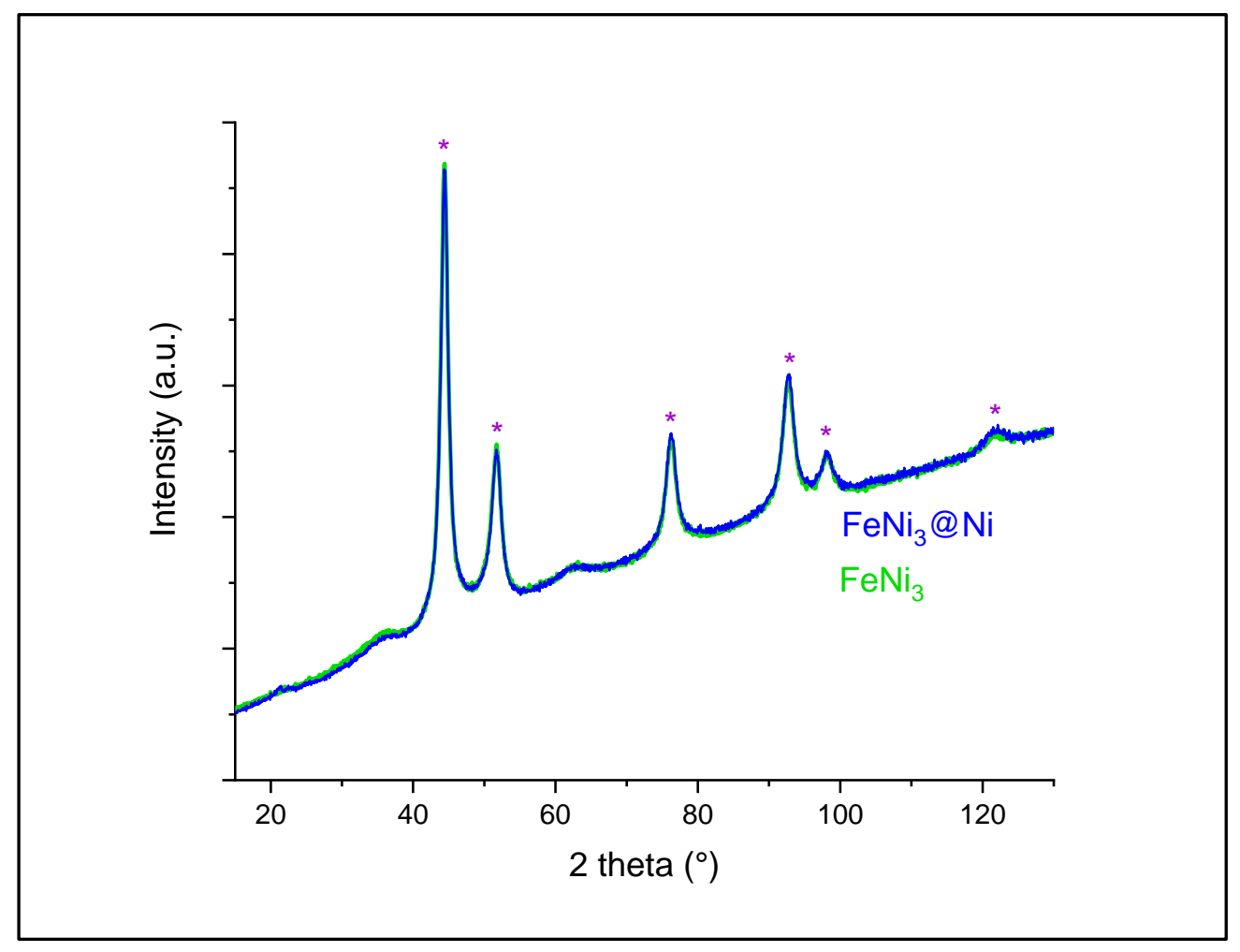

Figure 5: X-ray diffractograms of (i) $\mathrm{FeNi}_{3}$ and (ii) FeNi3 @Ni NPs. The stars correspond to cubic Ni (PDF card 00-004-0850).

Table 1: XRD peaks used to determine the crystallites size of nanoparticles

\begin{tabular}{|c|c|c|c|c|c|c|}
\hline Materials & $\begin{array}{c}\mathrm{Ni}_{\mathrm{HI}} \text { and } \\
\mathrm{Ni}_{\text {polyol }} \text { cubic } \\
\text { phase }\end{array}$ & $\begin{array}{c}\mathrm{Ni}_{\mathrm{HI}} \\
\text { hexagonal } \\
\text { phase }\end{array}$ & $\begin{array}{c}\text { Ni/ATO } \\
\text { cubic phase }\end{array}$ & $\begin{array}{c}\mathrm{SnO}_{2} \\
\text { tetragonal } \\
\text { phase }\end{array}$ & $\begin{array}{c}\mathrm{FeNi}_{3}(@ \mathrm{Ni}) \\
\text { cubic Ni } \\
\text { phase }\end{array}$ & $\begin{array}{c}\mathrm{FeNi}_{3}(@ \mathrm{Ni}) \\
\text { cubic } \mathrm{Ni} \\
\text { phase } \mathrm{Fe} \\
\text { rhomboedric } \\
\text { phase }\end{array}$ \\
\hline Peaks & $(111),(200)$ & $(100),(102)$ & $(111),(220)$ & $(110),(101)$ & $(111),(220)$ & $(110),(214)$ \\
\hline
\end{tabular}

The elemental analyses performed by ICP-MS confirm the composition of the catalysts (Table 2). Traces of Pt were found too for the pure Ni NPs (unsupported or not), in agreement 
with the synthesis routes employed (2.8 at.\% of Pt, which corresponds to $\sim 0.01$ wt.\% of Pt, was used to start the nucleation for Ni NPs syntheses).

Table 2: ICP-MS elemental analyses of some of the tested catalyst materials

\begin{tabular}{|l|rr|rrr|rr|}
\hline Materials & \multicolumn{2}{|c|}{$\mathrm{Ni}_{\mathrm{HI}}$} & \multicolumn{3}{|c|}{$\mathrm{Ni} / \mathrm{ATO}$} & \multicolumn{3}{|c|}{$\mathrm{Ni}_{\text {polyol }}$} \\
& $\mathrm{Ni}$ & $\mathrm{Pt}$ & $\mathrm{Ni}$ & $\mathrm{Sb}$ & $\mathrm{Sn}$ & $\mathrm{Ni}$ & $\mathrm{Pt}$ \\
\hline Atomic \% & 97.2 & 2.8 & 23.8 & 67.7 & 8.5 & 98.6 & 1.4 \\
\hline
\end{tabular}

Chemical analyses were performed on $\mathrm{FeNi}_{3}$ NPs by ICP-MS too, revealing a global composition of 29 at.\% $\mathrm{Fe}$ and 71 at.\% $\mathrm{Ni}$, in agreement with the targeted values $\left(\mathrm{FeNi}_{3}\right)$.

\subsection{Electrochemical characterizations}

Figure 6 (a) displays one-cycle LSVs of the different catalysts in the HER side. Classical benchmark $\mathrm{Pt} / \mathrm{C}$ was also characterized for comparison. $\mathrm{Ni}_{\text {polyol }}$ voltamperograms are not presented as the activity of this sample was weak, due to extensive surface oxidation, which was confirmed by its reduction under the electron beam while performing TEM observations. Besides, the particles were small and hence unstable in electrochemistry. These NPs were deposited onto ATO at a loading of 20 wt.\% to form $\mathrm{Ni}_{\text {polyol }}$ supported by ATO.

The voltamperograms show that the materials are not equivalent in terms of activity. The HER performances decrease in the following order: $\mathrm{Pt} / \mathrm{C}>\mathrm{Ni} / \mathrm{ATO}>\mathrm{Ni}_{\mathrm{HI}}>\mathrm{FeC} @ \mathrm{Ni}>$ $\mathrm{FeNi}_{3} @ \mathrm{Ni}$. All non-PGM electrodes were loaded at $200 \mu \mathrm{g} / \mathrm{cm}^{2}$ for the catalyst, while Pt/C was loaded at $20 \mu \mathrm{g} / \mathrm{cm}^{2}$. The loading for non-PGM materials was chosen ten times higher as the activity was weak at $20 \mu \mathrm{g} / \mathrm{cm}^{2}$. Besides, as these materials do not belong to PGM, a larger amount of them can be used without compromising the applicability of the materials in practice. The onset potentials determined at $j=10 \mathrm{~mA} / \mathrm{cm}^{2}$ are presented in Table 3. It is found at $E=-$ 
$0.29 \mathrm{~V} v s$. RHE for the best HER catalysts, far away from Pt/C $(E=-0.08 \mathrm{~V} v s$. RHE). The $\mathrm{FeNi}_{3}$ HER performances are not shown because their activity was too low.

Figure 6 (b) presents the average overpotentials $v s$. five values of the geometric current density: $j_{\text {geom }}=5,10,25,50$ and $100 \mathrm{~mA} / \mathrm{cm}^{2}$. The error bars account for the standard deviation; they might indicate, if they are large, a possible dissolution of the catalysts, leading to activity decrease with the number of cycles. This degradation of the performances is not much observed in the HER side, which is classical in alkaline (and acidic) water electrolysis: materials durability issues are more significant at the oxygen electrode, owing to the very intense oxidizing conditions experienced at this electrode [9][11][35]. Ni/ATO is an exception, a larger error bar is observed. The decreasing size of these bars with higher current density value is only due to the few points we were able to record before dissolution of the catalyst. The average overpotentials increase exponentially with the current, in agreement with the Butler-Volmer law, which means that the reactions are kinetically-limited by charge-transfer in these conditions.

It was decided to focus on $\mathrm{Ni}_{\mathrm{HI}}$ as the non-noble HER catalyst as it exhibited almost the best performances of the non-PGM catalysts. Ni/ATO was not selected because we observed dissolution of this catalyst in the alkaline media, as shown on Figure 6(b). Electrodes with different loadings of catalyst were studied, while keeping the same DI water/Nafion and DI water/IPA volume ratio. Figure 6(c) indicates that the $\mathrm{Ni}_{\mathrm{HI}}$ activity is the best at $200 \mu \mathrm{g} / \mathrm{cm}^{2}$, and then it decreases to $1000 \mu \mathrm{g} / \mathrm{cm}^{2}$. This trend can possibly be due to the detrimental active layer thickness effects; too thick layers could prevent hydroxide ions access to all active sites and more intense masking by bubbles build-up inside the active layer [32]; too thin layers are obviously limited by the number of active sites at the electrode. The performances of the best non-PGM electrode remain far below the Pt kinetics, which is a classical bias of alkaline HER/HOR [36]. Ni/ATO 20\% displays similar activity than Ni for an equivalent Ni catalyst 
loading, before dissolution. Ni synthesized by the polyol method shows lower activity, similar as $\mathrm{Ni}_{\mathrm{HI}} 1000 \mu \mathrm{g} / \mathrm{cm}^{2}$.

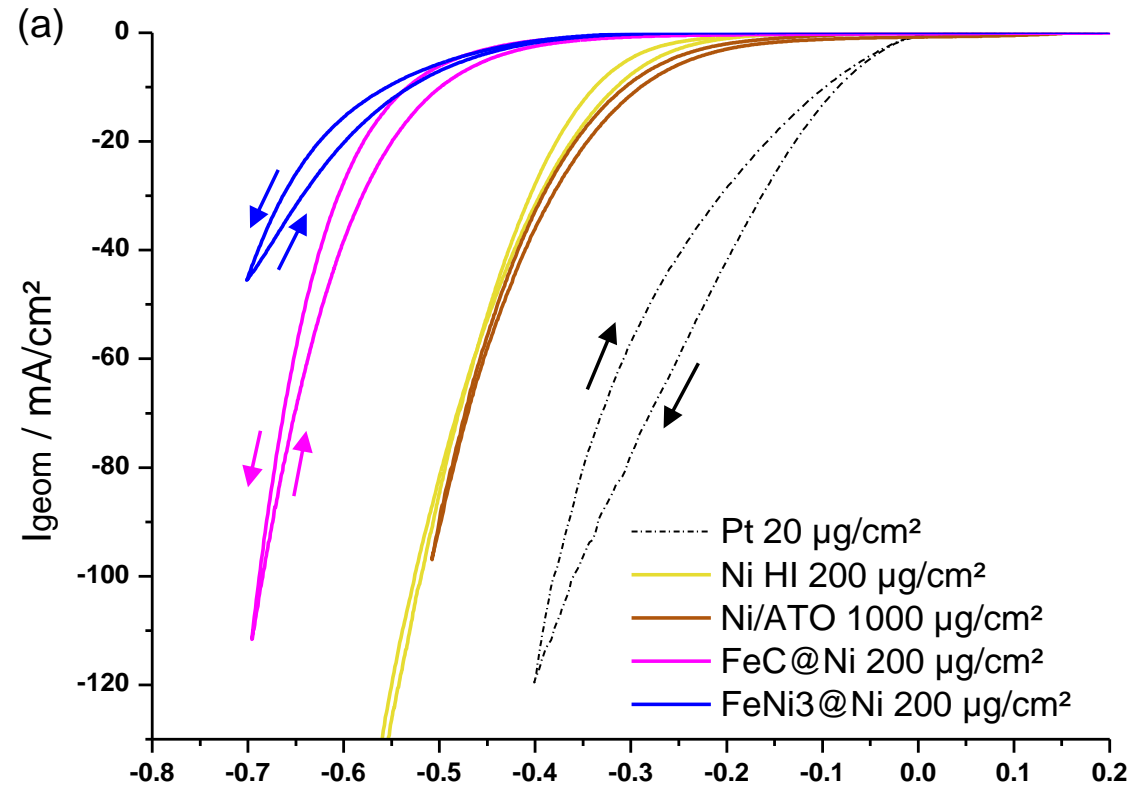

E- iR vs. RHE / V

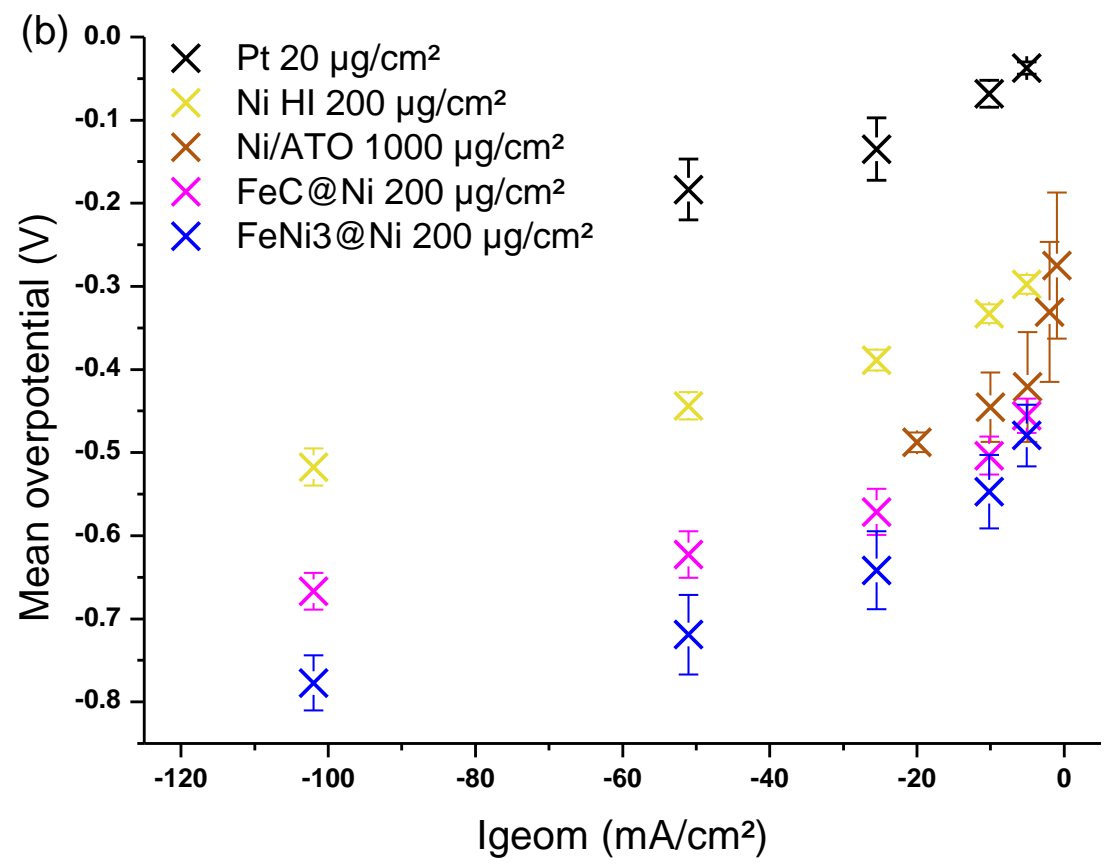




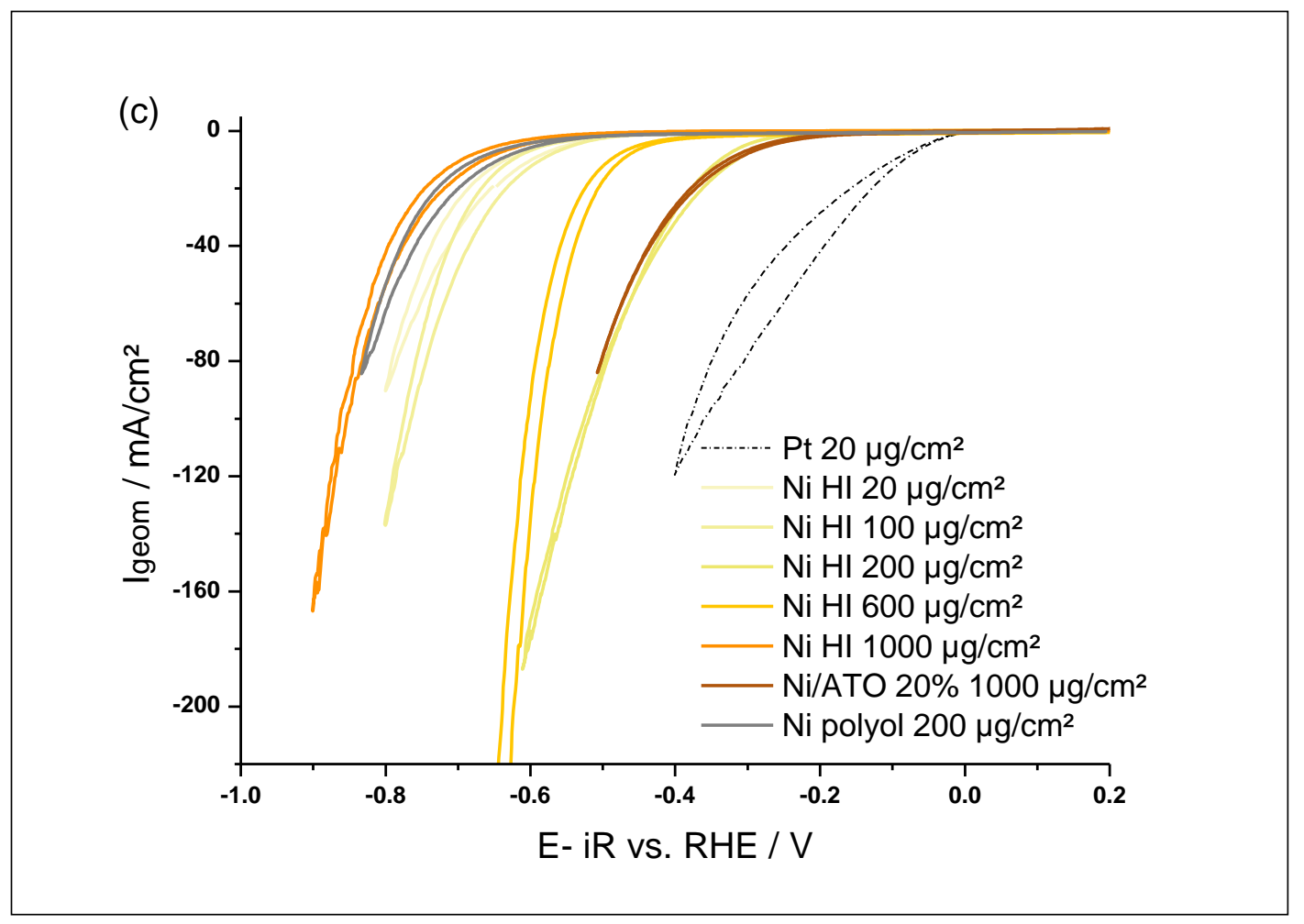

Figure 6: Electrochemical characterization of different catalysts compared to current benchmark (Pt/C in the HER side), measured in RDE setup in $1 \mathrm{M} \mathrm{KOH}$. (a) One-cycle Linear sweep voltammetry (LSV) of different catalysts recorded at a scan rate of $5 \mathrm{mV} / \mathrm{s}$, arrows indicate the scan direction (b) Mean overpotentials recorded at different $I_{\text {geom }}$ values $\left(5,10,25,50,100 \mathrm{~mA} / \mathrm{cm}^{2}\right)$. The error bars correspond to standard deviation, (c) One-cycle LSV of different $\mathrm{Ni}_{\mathrm{HI}}$ loadings recorded at a scan rate of $5 \mathrm{mV} / \mathrm{s}$.

Figure 7 (a) presents one cycle of LSV of different catalysts in the OER side. Unsupported commercial $\mathrm{IrO}_{2}$ was also characterized for comparison, as it is a (commercial) benchmark for the reaction. The OER performances decrease in the following order: $\mathrm{FeNi}_{3} @ \mathrm{Ni}$ $>\mathrm{FeNi}_{3} \sim \mathrm{Ni}_{\mathrm{HI}}>\mathrm{IrO}_{2}>\mathrm{FeC} @ \mathrm{Ni}>\mathrm{Ni} / \mathrm{ATO}$. The lowest onset potential observed here is at $E=$ $1.56 \mathrm{~V} v s$. RHE for the best non-PGM OER catalyst, slightly better than for $\operatorname{IrO}_{2}(E=1.60 \mathrm{~V}$ vs. RHE, this value being consistent with other studies [12]). Comparing $\mathrm{FeNi}_{3}$ and $\mathrm{FeNi}_{3} @ \mathrm{Ni}$ indicates that the Ni surface doping does enhance OER activity. 
Figure 7 (b) presents the average overpotentials $v$ s. five values of the geometric current density. In OER, dissolution is observed (this is, unfortunately, very classical for OER catalysts, especially in alkaline environments). The dissolution is more obvious at a loading of $20 \mu \mathrm{g} / \mathrm{cm}^{2}$ for $\mathrm{FeNi}_{3}$ and $\mathrm{FeC} @ \mathrm{Ni}$, owing to the least presence of catalyst material in the thin-film RDE. The same trend is observed for Ni/ATO. Again, the reactions are kinetically-limited by chargetransfer in these conditions, in agreement with the Butler-Volmer law.

A loading survey was made, this time on $\mathrm{FeNi}_{3}$. More specifically, $\mathrm{FeNi}_{3}$ was preferred to $\mathrm{FeNi}_{3} @ \mathrm{Ni}$ because its synthesis is twice shorter and its heating properties are slightly better [24]. Figure 7(c) indicates that the activity of $\mathrm{FeNi}_{3}$ increases from 20 to $100 \mu \mathrm{g} / \mathrm{cm}^{2}$ and then decreases from 100 to $5000 \mu \mathrm{g} / \mathrm{cm}^{2}$ for $\mathrm{FeNi}_{3}$ [37][38]. In OER, the activity of the non-PGM electrode surpasses the $\mathrm{IrO}_{2}$ one, for a loading $c a$. ten times higher. Increasing the loading creates more active sites. However, at too high loading, detrimental effect are presents such as a heavier resistive layer, triggering a potential gradient preventing all active sites to be at the same oxidizing potential; oxygen bubbles entrapment [32], and the detaching of layers because of bubbles.

Better performances have been obtained in both the OER and HER with the new catalysts versus those obtained by Niether et al. with FeC@ Ni [15]. Activities similar and better than benchmark catalyst $\mathrm{IrO}_{2}$ have been recorded for OER, but HER catalysts stay far below the $\mathrm{Pt} / \mathrm{C}$ activity. 


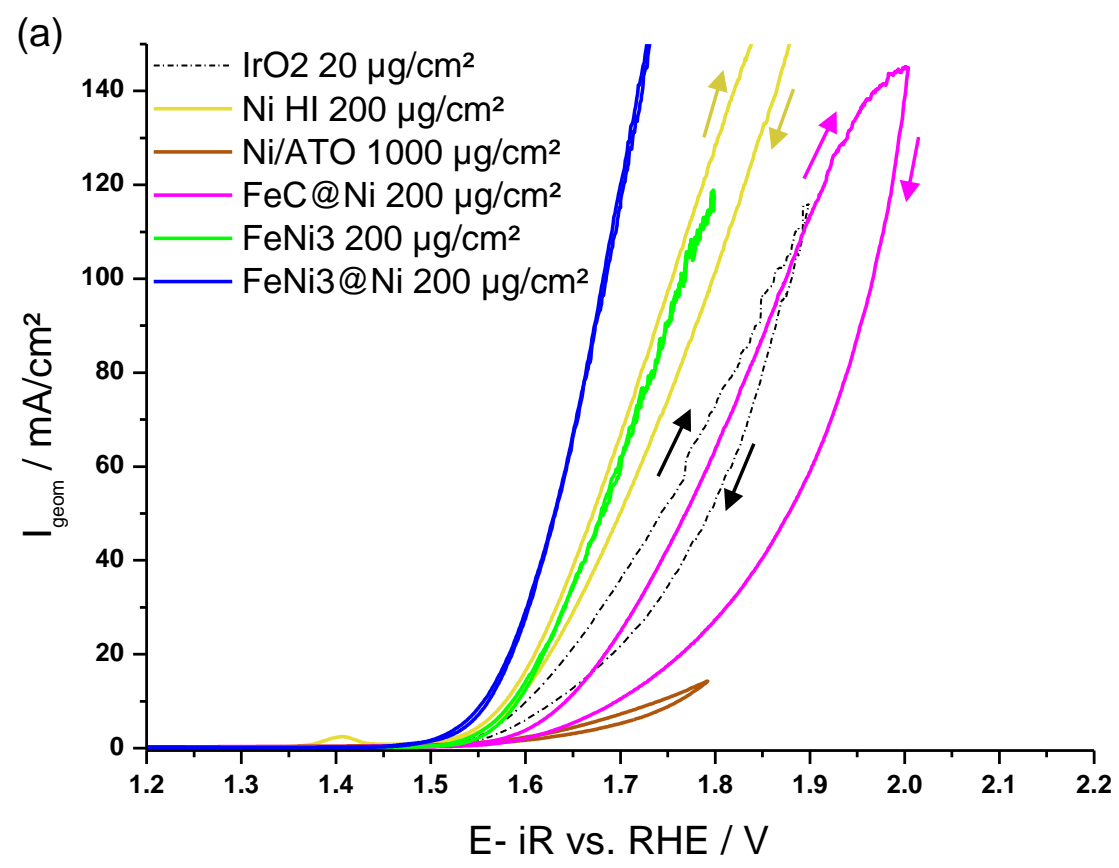

(b) $] \times$ Commercial IrO2 $20 \mu \mathrm{g} / \mathrm{cm}^{2}$

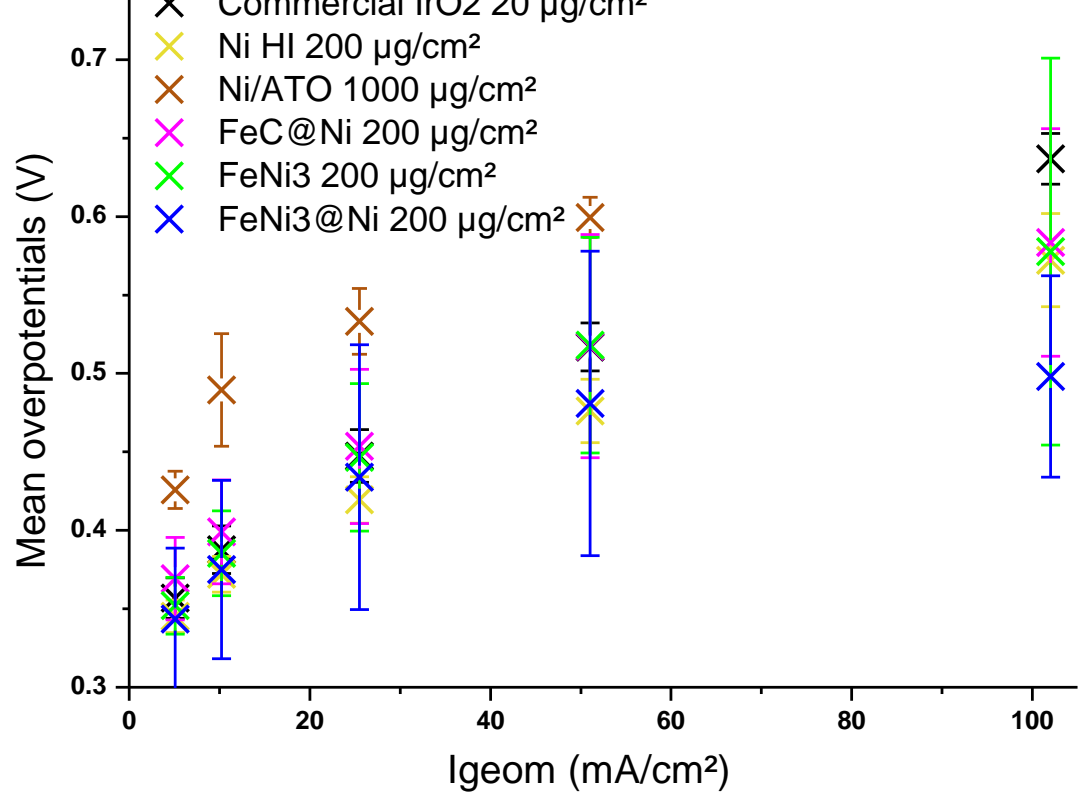




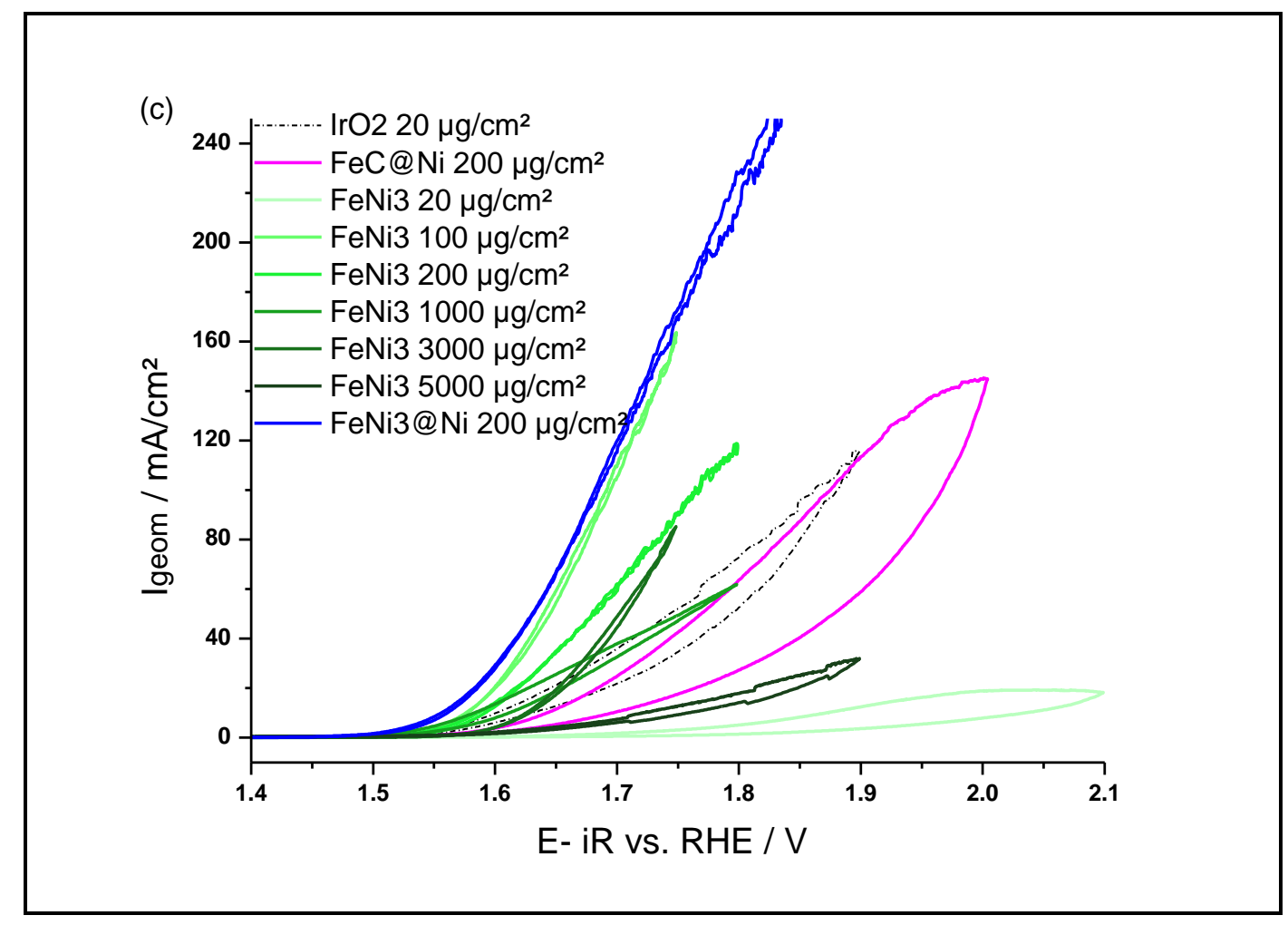

Figure 7: Electrochemical characterization of different catalysts compared to current benchmark (unsupported $\mathrm{IrO}_{2}$ ), measured in $\mathrm{RDE}$ setup in $1 \mathrm{M} \mathrm{KOH}$. (a) One-cycle Linear sweep voltammetry (LSV) of different catalysts recorded at a scan rate of $5 \mathrm{mV} / \mathrm{s}$, arrows indicate the scan direction (b) Mean overpotentials recorded at different $I_{\text {geom }}$ values $(5,10$, $25,50,100 \mathrm{~mA} / \mathrm{cm}^{2}$ ). The error bars correspond to standard deviation, (c) One-cycle LSV of different $\mathrm{FeNi}_{3}$ loadings recorded at a scan rate of $5 \mathrm{mV} / \mathrm{s}$.

Table gathers the HER and OER performances obtained with the different catalysts tested herein. The authors point out that only the HER and OER potential measured for a current density were measured; at this rather small current density, it is believed that the mass-transfer limitation is still small, making of these values a marker of the intrinsic "charge-transfer kinetics" of the catalysts studied. In addition, the Tafel slopes were deliberately not reported in this table, because of (i) the hysteresis of the LSV curves in fig 6a and 7a and (ii) non-negligible 
mass-transfer hindrances at higher current densities, which would render awkward any precise calculation of Tafel slopes. In line with the previous sections of the paper, Table 3 summarizes that $\mathrm{Ni} / \mathrm{ATO}$ and $\mathrm{Ni}_{\mathrm{HI}}$ are the best home-made catalysts on the HER side (but far less active than the Pt/C benchmark). On the OER side, the $\mathrm{FeNi}_{3}$ and $\mathrm{FeNi}_{3} @ \mathrm{Ni}$ are the best catalysts, not only outperforming the FeC@Ni sample tested in Ref. [15], but also the present OER benchmark (unsupported $\mathrm{IrO}_{2}$ ). This results holds clear promises for AMF-enhanced AWE using these materials.

Table 3: Nanoparticles size and HER / OER performances of the catalysts studied.

\begin{tabular}{|c|c|c|c|}
\hline Catalysts & $\begin{array}{c}\text { NPs size } \\
(\mathrm{nm})\end{array}$ & $\begin{array}{c}\text { HER potential at } 10 \mathrm{~mA} / \mathrm{cm}^{2} \\
\text { (V vs. RHE) }\end{array}$ & $\begin{array}{c}\text { OER potential at } 10 \mathrm{~mA} / \mathrm{cm}^{2} \\
\text { (V vs. RHE) }\end{array}$ \\
\hline $\mathrm{Pt} / \mathrm{C}\left(20 \mu \mathrm{g} / \mathrm{cm}^{2}\right)$ & 2 to 3 & -0.08 & I \\
\hline $\begin{array}{c}\mathrm{IrO}_{2} \operatorname{comm}(20 \\
\left.\mu \mathrm{g} / \mathrm{cm}^{2}\right)\end{array}$ & & I & 1.6 \\
\hline $\mathrm{Ni}_{\mathrm{HI}}$ & 69 & -0.32 & 1.58 \\
\hline $\mathrm{Ni} / \mathrm{ATO}$ & 5 & -0.29 & 1.74 \\
\hline $\mathrm{FeNi}_{3}$ & 17 & (too low) & 1.59 \\
\hline $\mathrm{FeNi}_{3} @ \mathrm{Ni}$ & 18.6 & -0.55 & 1.56 \\
\hline FeC@Ni & 15 & -0.53 & 1.64 \\
\hline
\end{tabular}




\section{Conclusion}

Several catalytic particles have been characterized by various structural analyses as well as electrochemical RDE experiments. Nanoparticles of Ni synthesized by two ways, the hot injection method and the polyol method, and Ni/ATO have been mainly characterized in HER. A study of the loading of $\mathrm{Ni}_{\mathrm{HI}} \mathrm{NPs}$ and $\mathrm{FeNi}_{3}$ has been carried. Good performances were demonstrated with an onset potential $E=-0.29 \mathrm{~V} v s$. RHE, yet far below the Pt/C activity $(E=$ -0.08 V vs. RHE). FeNi3, $\mathrm{FeNi}_{3} @ \mathrm{Ni}$ and $\mathrm{Ni}_{\mathrm{HI}} \mathrm{NPs}$ have been characterized in OER. The performances of these NPs are better than the benchmark catalyst consisting of unsupported $\mathrm{IrO}_{2}$, and better than previous the magnetic catalyst used FeC@ Ni [6]. A loading study indicates than the activity of $\mathrm{FeNi}_{3}$ is better at $100 \mu \mathrm{g} / \mathrm{cm}^{2}$ with an onset potential at $1.5 \mathrm{~V} v s$. RHE. These Fe-based nanoparticles display interesting properties for OER and will be tested for magnetic induction-assisted electrocatalysis.

\section{Acknowledgments}

This work has been performed in the frame of the Hy-WalHy project, funded by the French National Research Agency (ANR-1-CE05-0017). The LPCNO authors thank ERC Advanced Grant (MONACAT 2015-694159). The LPCNO is acknowledge for the NPs syntheses. Christian Beauger, from the PERSEE group of ARMINES in Sophia Antipolis is greatly acknowledged for having provided the ATO support used herein.

Vivien Gatard did all the electrochemical tests, the TEM pictures of the Ni-based catalysts with the help of Marian Chatenet, and helped doing ICP-MS measurements with Vincent Martin. Déborah De Masi and Irene Mustiele did the $\mathrm{FeNi}_{3}$ and the $\mathrm{FeNi}_{3} @ \mathrm{Ni}$ syntheses while Pier-Francesco Fazzini characterized them with TEM pictures. Raphaël Chattot did all the Ni-based material syntheses. Juan Manuel Asensio Revert did the FeC@ Ni synthesis. 
Thierry Encinas performed all the XRD measurements. VG, JD and MC essentially wrote and reviewed the contribution.

\section{References}

[1] P.C.K. Vesborg, T.F. Jaramillo, Addressing the terawatt challenge: scalability in the supply of chemical elements for renewable energy, RSC Adv. 2 (2012) 7933. https://doi.org/10.1039/c2ra20839c.

[2] I. Dincer, Environmental and sustainability aspects of hydrogen and fuel cell systems, Int. J. Energy Res. (2007) 29-55. https://doi.org/https://doi.org/10.1002/er.

[3] S. Ehsan, M.A. Wahid, Hydrogen production from renewable and sustainable energy resources: Promising green energy carrier for clean development, Renew. Sustain. Energy Rev. 57 (2016) 850-866. https://doi.org/10.1016/j.rser.2015.12.112.

[4] K. Zeng, D. Zhang, Recent progress in alkaline water electrolysis for hydrogen production and applications, Prog. Energy Combust. Sci. 36 (2010) 307-326. https://doi.org/10.1016/j.pecs.2009.11.002.

[5] U. Bossel, Does a Hydrogen Economy Make Sense?, IEEE. 94 (2006) 1826. https://doi.org/10.1109/JPROC.2006.883715.

[6] J. Chi, H. Yu, Water electrolysis based on renewable energy for hydrogen production, Chinese J. Catal. 39 (2018) 390-394. https://doi.org/10.1016/S1872-2067(17)62949-8.

[7] L.F.L. Oliveira, S. Laref, E. Mayousse, A.A. Franco, A multiscale physical model for the transient analysis of PEM water electrolyzer anodes, Phys. Chem. Chem. Phys. 14 (2012) 10215-10224. https://doi.org/10.1039/c2cp23300b.

[8] S. Cherevko, T. Reier, A.R. Zeradjanin, Z. Pawolek, P. Strasser, K.J.J. Mayrhofer, Electrochemistry Communications Stability of nanostructured iridium oxide electrocatalysts during oxygen evolution reaction in acidic environment, Electrochem. 
Commun. 48 (2014) 81-85. https://doi.org/10.1016/j.elecom.2014.08.027.

[9] S. Cherevko, S. Geiger, O. Kasian, N. Kulyk, J.P. Grote, A. Savan, B.R. Shrestha, S. Merzlikin, B. Breitbach, A. Ludwig, K.J.J. Mayrhofer, Oxygen and hydrogen evolution reactions on $\mathrm{Ru}, \mathrm{RuO} 2, \mathrm{Ir}$, and $\mathrm{IrO} 2$ thin film electrodes in acidic and alkaline electrolytes: A comparative study on activity and stability, Catal. Today. 262 (2016) 170-180. https://doi.org/10.1016/j.cattod.2015.08.014.

[10] S. Geiger, O. Kasian, A.M. Mingers, K.J.J. Mayrhofer, S. Cherevko, Stability limits of tin-based electrocatalyst supports, Sci. Rep. (2017) 3-9. https://doi.org/10.1038/s41598017-04079-9.

[11] O. Kasian, S. Geiger, M. Schalenbach, A.M. Mingers, A. Savan, A. Ludwig, S. Cherevko, K.J.J. Mayrhofer, Using Instability of a Non-stoichiometric Mixed Oxide Oxygen Evolution Catalyst As a Tool to Improve Its Electrocatalytic Performance, Electrocatalysis. 9 (2018) 139-145. https://doi.org/10.1007/s12678-017-0394-6.

[12] F. Claudel, Degradation Mechanisms of Oxygen Evolution Reaction Electrocatalysts: A Combined Identical-Location Transmission Electron Microscopy and X-ray Photoelectron Spectroscopy Study, ACS Catal. 9 (2019) 4688-4698. https://doi.org/10.1021/acscatal.9b00280.

[13] L. Sola-Hernandez, F. Claudel, F. Maillard, C. Beauger, Doped tin oxide aerogels as oxygen evolution reaction catalyst supports, Int. J. Hydrog. Energy. 4 (2019) 2433124341. https://doi.org/10.1016/j.ijhydene.2019.07.152.

[14] A. Damien, Hydrogène par électrolyse de l'eau, Tech. l’Ingénieur. (1992).

[15] C. Niether, S. Faure, A. Bordet, J. Deseure, M. Chatenet, J. Carrey, B. Chaudret, A. Rouet, Improved water electrolysis using magnetic heating of $\mathrm{FeC}-\mathrm{Ni}$ core-shell nanoparticles, Nat. Energy. 3 (2018) 476-483. https://doi.org/10.1038/s41560-0180132-1. 
[16] A. Bordet, L. Lacroix, P. Fazzini, J. Carrey, K. Soulantica, B. Chaudret, Heterogeneous Catalysis Hot Paper Magnetically Induced Continuous CO2 Hydrogenation Using Composite Iron Carbide Nanoparticles of Exceptionally High Heating Power, Communications. (2016) 1-6. https://doi.org/10.1002/anie.201609477.

[17] J. Carrey, B. Mehdaoui, M. Respaud, Simple models for dynamic hysteresis loop calculations of magnetic single-domain nanoparticles: Application to magnetic hyperthermia optimization, J. Appl. Phys. $109 \quad$ (2011) 083921. https://doi.org/10.1063/1.3551582.

[18] M. Schalenbach, O. Kasian, K.J.J. Mayrhofer, An alkaline water electrolyzer with nickel electrodes enables efficient high current density operation, Int. J. Hydrog. Energy. (2018) 1-7. https://doi.org/10.1016/j.ijhydene.2018.04.219.

[19] M. Görlin, P. Chernev, J. Ferreira, D. Arau, T. Reier, S. Dresp, B. Paul, R. Kra, H. Dau, P. Strasser, Oxygen Evolution Reaction Dynamics, Faradaic Charge Efficiency, and the Active Metal Redox States of Ni-Fe Oxide Water Splitting Electrocatalysts, J. Am. Chem. Soc. 138 (2016) 5603-5614. https://doi.org/10.1021/jacs.6b00332.

[20] M. Görlin, J. Ferreira, D. Arau, H. Schmies, D. Bernsmeier, S. Dresp, M. Gliech, Z. Jusys, P. Chernev, R. Kraehnert, H. Dau, P. Strasser, Tracking Catalyst Redox States and Reaction Dynamics in $\mathrm{Ni}-\mathrm{Fe}$ Oxyhydroxide Oxygen Evolution Reaction Electrocatalysts: The Role of Catalyst Support and Electrolyte pH, J. Am. Chem. Soc. 139 (2017) 2070-2082. https://doi.org/10.1021/jacs.6b12250.

[21] M. Görlin, P. Chernev, P. Paciok, C.-W. Tai, F. de A. Jorge, T. Reier, M. Heggen, R. Dunin-Borkowski, P. Strasser, H. Dau, Formation of unexpectedly active Ni-Fe oxygen evolution electrocatalysts by physically mixing $\mathrm{Ni}$ and $\mathrm{Fe}$ oxyhydroxydes, Chem. Commun. 55 (2019) 818-821. https://doi.org/10.1039/c8cc06410e.

[22] F. Moureaux, P. Stevens, G. Toussaint, M. Chatenet, Development of an oxygen- 
evolution electrode from 316L stainless steel: Application to the oxygen evolution reaction in aqueous lithium e air batteries, J. Power Sources. 229 (2013) 123-132. https://doi.org/10.1016/j.jpowsour.2012.11.133.

[23] F. Moureaux, P. Stevens, G. Toussaint, M. Chatenet, Environmental Timely-activated 316L stainless steel: A low cost, durable and active electrode for oxygen evolution reaction in concentrated alkaline environments, Appl. Catal. B Environ. 258 (2019) 117963. https://doi.org/10.1016/j.apcatb.2019.117963.

[24] D. De Masi, P.-F. Fazzini, B. Chaudret, No Title, Submitted. (2019).

[25] R. Chattot, O. Le Bacq, V. Beermann, S. Kühl, J. Herranz, S. Henning, L. Kühn, T. Asset, L. Guétaz, G. Renou, J. Drnec, P. Bordet, A. Pasturel, A. Eychmüller, T.J. Schmidt, P. Strasser, L. Dubau, F. Maillard, Surface distortion as a unifying concept and descriptor in oxygen reduction reaction electrocatalysis, Nat. Mater. 17 (2018) 827-833. https://doi.org/10.1038/s41563-018-0133-2.

[26] G. Cognard, G. Ozouf, C. Beauger, G. Berthomé, D. Riassetto, L. Dubau, R. Chattot, M. Chatenet, F. Maillard, Benefits and limitations of Pt nanoparticles supported on highly porous antimony-doped tin dioxide aerogel as alternative cathode material for protonexchange membrane fuel cells, Appl. Catal. B Environ. 201 (2017) 381-390. https://doi.org/10.1016/j.apcatb.2016.08.010.

[27] Y. Garsany, J. Ge, J. St-Pierre, R. Rocheleau, K.E. Swider-Lyons, Standardizing ThinFilm Rotating Disk Electrode Measurements of the Oxygen Reduction Activity of Pt/C, ECS Trans. 58 (2013) 3-14. https://doi.org/10.1149/05801.0003ecst.

[28] Y. Garsany, J. Ge, J. St-pierre, R. Rocheleau, Analytical Procedure for Accurate Comparison of Rotating Disk Electrode Results for the Oxygen Reduction Activity of Pt/C, J. Electrochem. Soc. 161 (2014) 628-640. https://doi.org/10.1149/2.036405jes.

[29] Y. Garsany, I.L. Singer, K.E. Swider-lyons, Impact of film drying procedures on RDE 
characterization of Pt/VC electrocatalysts, J. Electroanal. Chem. 662 (2011) 396-406. https://doi.org/10.1016/j.jelechem.2011.09.016.

[30] B.G. Pollet, J.T.E. Goh, The importance of ultrasonic parameters in the preparation of fuel cell catalyst inks, Electrochim. Acta. $128 \quad$ (2014) 292-303. https://doi.org/10.1016/j.electacta.2013.09.160.

[31] B.G. Pollet, Let' s Not Ignore the Ultrasonic Effects on the Preparation of Fuel Cell Materials, Electrocatalysis. 5 (2014) 330-343. https://doi.org/10.1007/s12678-0140211-4.

[32] H.A. El-sayed, A. Weiß, L.F. Olbrich, G.P. Putro, H.A. Gasteiger, OER Catalyst Stability Investigation Using RDE Technique: A Stability Measure or an Artifact?, J. Electrochem. Soc. 166 (2019) 458-464. https://doi.org/10.1149/2.0301908jes.

[33] A. Zadick, L. Dubau, N. Sergent, G. Berthomé, M. Chatenet, Huge instability of Pt/C catalysts in alkaline medium, ACS Catal. (2015) 1-9.

[34] F. Arteaga-cardona, K. Rojas-rojas, R. Costo, M.A. Mendez-rojas, Improving the magnetic heating by disaggregating nanoparticles, J. Alloys Compd. 663 (2016) 636644. https://doi.org/10.1016/j.jallcom.2015.10.285.

[35] M. Schalenbach, O. Kasian, M. Ledenecker, F.D. Speck, A.M. Mingers, K.J.J. Mayrhofer, S. Cherevko, The Electrochemical Dissolution of Noble Metals in Alkaline Media, Electrocatalysis. 9 (2018) 153-161. https://doi.org/10.1007/s12678-017-0438-y.

[36] E.S. Davydova, S. Mukerjee, D.R. Dekel, Electrocatalysts for Hydrogen Oxidation Reaction in Alkaline Electrolytes, ACS Catal. 8 (2018) 6665-6690. https://doi.org/10.1021/acscatal.8b00689.

[37] Y. Qiu, L. Xin, W. Li, Electrocatalytic Oxygen Evolution over Supported Small Amorphous Ni-Fe Nanoparticles in Alkaline Electrolyte, ACS Pub. 30 (2014) 7893. https://doi.org/10.1021/la501246e. 
[38] N. Danilovic, R. Subbaraman, D. Strmcnik, K. Chang, A.P. Paulikas, V.R. Stamenkovic, N.M. Markovic, Enhancing the Alkaline Hydrogen Evolution Reaction Activity through the Bifunctionality of $\mathrm{Ni}(\mathrm{OH}) 2 /$ Metal Catalysts **, Angew. Chem. Int. Ed. 51 (2012) 12495-12498. https://doi.org/10.1002/anie.201204842. 